\title{
UMA LEITURA EM PARALELO OBLÍQUO: "A PROFECIA" DE BRÁS CUBAS, "O DELÍRIO" DE JOÃO DE PATMOS ${ }^{1}$
}

\author{
Daiane Carneiro Pimentel e Glauber Pereira Quintão \\ Universidade Federal de Minas Gerais \\ Belo Horizonte (MG), Brasil
}

\begin{abstract}
Resumo: Este artigo parte da diferenciação entre as possibilidades de análise literária que tomam como perspectiva ou a produção das obras, que amarra as obras ao seu momento de aparição histórica, ou a recepção, que se despoja da cronologia e permite verificar que a leitura de uma obra altera a de outra, independentemente de qual tenha sido produzida primeiro. Assim, segue-se a análise comparada de "O delírio", de Memórias póstumas de Brás Cubas, de Machado de Assis, e do Apocalipse de João de Patmos. Cumpre verificar como a leitura do texto machadiano permite a releitura do texto bíblico, relativizando sua pretensa posse da verdade, bem como o texto de João permite a releitura de "O delírio", como se tangesse, de algum modo, a verdade.
\end{abstract}

Palavras-chave: Machado de Assis; Memórias póstumas de Brás Cubas; Apocalipse; recepção.

\section{A parallel and oblique reading: "The prophecy", by Brás Cubas, "The delirium", by John of Patmos}

\begin{abstract}
This article starts from the theoretical distinction between two possibilities of literary analysis, one that keeps the focus on the historical moment in which the text was written, tying it to its historical context; the other from the point of view of the reception, a mode of interpretation that accepts the intertwinement of texts and their further modification by one another, regardless of which was written first. Thereby, this is a comparative analysis of " $O$ delírio", from Memórias póstumas de Brás Cubas, by Machado de Assis, and the Apocalypse by John of Patmos. The reading of Machado's text allows a rereading of the biblical text and relativizes its supposed truth, just as Patmos's text allows us to reread "O delírio" as one that could reach the truth.
\end{abstract}

\footnotetext{
${ }^{1}$ A aproximação entre os dois textos nos foi sugerida pelo professor José Raimundo Maia Neto (perspicaz estudioso da obra de Machado de Assis), mas sob a perspectiva do ceticismo, enquanto aqui se explora a via da recepção narrativa.
} 
Keywords: Machado de Assis; Memórias póstumas de Brás Cubas; Apocalypse; reception.

Leo H. Hoek, no ensaio intitulado "A transposição intersemiótica",2 elabora uma distinção que demarca com clareza a perspectiva da recepção e sem a qual se deixam confundir os critérios da sucessividade e da simultaneidade. A despeito de que Hoek tenha em vista relações intersemióticas, aqui essa distinção simplesmente nos ajuda a pensar em que plano estabelecer a relação entre duas obras cujo suporte é verbal: ou no plano da produção, ou no da recepção. Enquanto naquele se deve respeitar a sucessividade cronológica, neste é possível não se amarrar às condições históricas de sucessão. Afinal, segundo Hoek, no plano da recepção, são possíveis as seguintes ações: 1) adotar a sucessividade, isto é, o trabalho que foi produzido primeiramente terá sido, de alguma forma, apropriado pelo que lhe sucede; 2) inverter a sucessividade, isto é, pensar como uma obra posterior influenciou a recepção de uma obra que foi produzida primeiramente; 3) pensar as duas obras produzidas em épocas ou lugares diferentes simultaneamente.

A simultaneidade da recepção, para o nosso intento, não consiste evidentemente em que se possam ler dois textos ao mesmo tempo - a leitura possui, nesse sentido, a inescapável condição linear e sucessiva tão bem pontuada por Lessing, ${ }^{3}$ já o século XVIII. A simultaneidade de recepção a que nos voltamos refere-se à formação de uma interferência bilateral das imagens e dos recursos de textos cuja produção é marcada pela distância espaçotemporal, geográfica e histórica. O que se segue é, portanto, uma leitura em paralelo, digamos, oblíquo, de "O delírio", capítulo de Memórias póstumas de Brás Cubas, de Machado de Assis, e do livro bíblico do Apocalipse, de João de Patmos.

Esta análise é despretensiosa. Primeiramente por renunciar à abordagem do tipo que respeita a sucessividade cronológica da produção das obras. Isso, pois, livra-

\footnotetext{
${ }^{2}$ HOEK, Leo H. A transposição intersemiótica: por uma classificação pragmática. Trad. Thaïs Flores N. Diniz. In: ARBEX, Márcia (Org.). Poéticas do visível. Belo Horizonte: Faculdade de Letras - UFMG, 2006. p. 167-190.

${ }^{3}$ Cf. MOSER, Walter. As relações entre as artes: por uma arqueologia da intermidialidade. In: Aletria. Revista de estudos de literatura. v. 14, caderno temático "Intermidialidade". Belo Horizonte, jul./dez.2006. p. 44.
} 
nos do trabalho sistemático de levantar exaustivamente referências e embasamentos que confirmem a conjectura de que "O delírio", sendo posterior ao Apocalipse, retoma-o e em que aspectos, precisamente, o faria, esgotando assim o seu processo composicional; ademais, livra-nos de ter de provar se verdadeiramente o segundo texto retoma e cita o primeiro. ${ }^{4}$ Talvez o autor o tenha mesmo realizado, mas não de forma tão consciente, nem como senhor de seu projeto composicional, atitude que lhe possibilitaria valer-se do Apocalipse de João de Patmos, de tal ou qual forma, para escrever o capítulo "O delírio".

Não desconsideramos que Afrânio Coutinho, em "Machado de Assis na literatura brasileira", 5 refere-se à Bíblia não só como um dos livros prediletos de Machado, mas também como uma das principais influências na concepção técnica e literária do escritor. Em contrapartida, escapamos desse espaço da produção do texto (e do momento autoral) porque o desenvolvimento linear e sucessivo da história talvez criasse uma hierarquização, ao menos, do momento de aparição de cada obra e, por conseguinte, implicasse uma determinada ordem da recepção, o que queremos evitar.

Nosso trabalho, portanto, difere fundamentalmente do de Leonardo de Almeida, em seu ensaio "A questão da biblioteca em Memórias póstumas de Brás Cubas". ${ }^{6}$ Segundo Almeida, as citações nas Memórias póstumas tomam um sentido dinâmico com a obra e, com isso, curtem-se ao sabor mordaz característico de Machado de Assis. Trata-se de uma mudança em relação ao Machado da "primeira fase", para quem citar era praticamente colar um pedaço de texto, que se comportava como uma cápsula, em citações ipsis littteris:

[...] a partir de Memórias póstumas de Brás Cubas, seu método de leitura passa a depurar as citações, sempre no intuito de subvertê-las à situação em que se encontram seus personagens. ${ }^{7}$

\footnotetext{
${ }^{4} \mathrm{O}$ segundo texto, portanto, seria aquele produzido mais tarde, de acordo com o tempo histórico.

5 COUTINHO, Afrânio. Machado de Assis na literatura brasileira. In: ASSIS, Machado de. Obra completa. Afrânio Coutinho (Org.). Rio de Janeiro: Nova Aguilar, 1962. p. 44.

${ }^{6}$ ALMEIDA, Leonardo V. A questão da biblioteca em Memórias póstumas de Brás Cubas. In: ROCHA, João Cezar de Castro (Org.). À roda de Machado de Assis: ficção, crônica e crítica. Chapecó (SC): Argos, 2006.

${ }^{7}$ Idem, p. 130.
} 
Ao se dedicar a verificar o funcionamento e o modo das citações, Almeida emprega o termo "original" para se referir ao texto-fonte, o que sugere que o referido crítico literário trabalha no plano da sucessividade e respeita a lógica da produção. Nesse contexto, ao leitor restaria o trabalho de decodificação das citações por meio da consulta aos textos originais. Almeida deixa, assim, de explorar a simultaneidade da recepção, pois, ao referir-se ao "original", que carrega a "conotação capsular" de ser "usado" de algum modo pela citação, é como se se referisse a algo fechado.

Ora, ao contrário de Almeida, que exige que o texto bíblico seja um original (pré-texto), a leitura que propomos é paratextual, isto é, coloca "O delírio" e o Apocalipse lado a lado e fora de suas hierarquias cronológicas, mas não impede que esses textos se imiscuam (por isso, um paralelo oblíquo), ainda que não sob a forma de uma síntese ou de um diálogo harmonioso. Nossa leitura não almeja, por conseguinte, revelar a inserção secreta ou explícita de um texto original operada por Machado de Assis entre as linhas, ou por trás de seu texto "segundo". Nesse sentido, vale ressaltar, no âmbito da recepção não existe um Apocalipse "puro" que, então, pudesse ser citado sem que já fosse ele também uma perspectiva, uma interpretação; sem que ele mesmo passasse a ser percebido diferentemente, pela interferência de um leitor o qual

[a]través de indícios dispersos deixados pelo texto, [...] reconhece e reconstrói o quadro "evocado como um fantasma visual", como se "um extrato de sentido e de ficção tivesse sido superposto, como se intercalado entre o quadro e a sua visão, como uma tela suplementar, diáfana, mas presente".

Da mesma forma, não pode existir "O delírio" "puro", pois, além de toda recepção implicar redução, ${ }^{9}$ toda uma cultura se nos interpõe.

Após essa propedêutica metodológica, argumentaremos, pelo confronto da aproximação e do afastamento possíveis, que "O delírio", de Machado de Assis, permite uma leitura dessacralizante do Apocalipse, de João de Patmos, conferindo ao texto

\footnotetext{
${ }^{8}$ LOUVEL, Liliane. Texte/image: imagens à lire, textes à voir. Rennes: Presses Universitaires de Rennes, 2002. Citado em: ARBEX, Márcia. Poéticas do visível: uma breve introdução. In: (Org.). Poéticas do visível, cit., p. 50.

${ }^{9}$ STIERLE, Karlheinz. Que significa a recepção dos textos ficcionais. Trad. Heidrun Krieger, Luiz Costa Lima e Peter Neumann. In: LIMA, Luiz Costa (Org.). A leitura e o leitor. Rio de Janeiro: Terra e Paz, 1979. p. 135.
} 
bíblico, por meio da paródia, uma leveza. Defenderemos, ainda, que o livro de João de Patmos, por sua vez, potencializa o humor mordaz do capítulo machadiano em questão, além de permitir que este seja lido enquanto visão profética.

$$
* * *
$$

No início das Memórias póstumas, no capítulo "Óbito do autor", o protagonista/narrador, Brás Cubas, ao se referir à preferência de sua estratégia narrativa, menciona Moisés:

Suposto o uso vulgar seja começar pelo nascimento, duas considerações me fizeram adotar diferente método: a primeira é que eu não sou propriamente um autor defunto, mas um defunto autor; a segunda é que o escrito ficaria assim mais galante e novo. Moisés, que também contou a sua morte, não a pôs no introito, mas no cabo: diferença radical entre este livro e o Pentateuco. ${ }^{10}$

Nesse trecho metalinguístico, o defunto autor expõe a sua autonomia diante de uma escolha de caráter literário. Como sujeito de sua escrita, ele decide realizar uma inversão cronológica e começar a narrar sua história pelo fim, o que o diferencia de Moisés, um dos supostos autores bíblicos. Acreditamos que a ideia de inversão também possa ser produtiva para o entendimento de como as Memórias póstumas, em especial seu capítulo "O delírio", e o livro Apocalipse se relacionam, pois ambos possuem marcadas dessemelhanças e semelhanças, se invertidos. Mas não se trata de uma inversão simples, que um espelho seria capaz de reverter e, com isso, mostrar textos/imagens iguais; uma interação pode ser descrita.

Cubas trata a inversão da cronologia de sua narrativa como um problema meramente preferencial: não é uma ordem dada pelo Divino, é uma questão de estilo literário. Expondo seus motivos pessoais e a vulgar opção de Moisés, ele nos induz a pensar quais teriam sido as preferências deste, bem como nós podemos pensar sobre as do profeta João de Patmos no momento da escritura do Apocalipse. Somos levados a inferir que o citado profeta também fez escolhas narrativas, estilísticas e retóricas ao

\footnotetext{
${ }^{10}$ ASSIS, Machado de. Obra completa. Afrânio Coutinho (Org.). Rio de Janeiro: Nova Aguilar, 1962. p.
} 513. 
escrever, pois isto é claro: ele escreveu e narrou. Além disso, tal como as Memórias póstumas, o Apocalipse se vale largamente da metalinguagem. Conforme salienta Bernart McGim, tanto o autor quanto o objetivo do Apocalipse "são claramente proclamados no princípio" do livro, ${ }^{11}$ o que evidencia um caráter metalinguístico que é explicitado também nas seguintes passagens: "Disse-me então: estas palavras são fiéis e

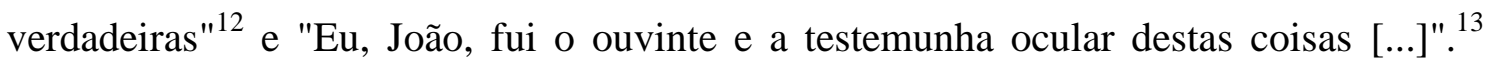
Uma vez que a metalinguagem pressupõe uma reflexão sobre a própria linguagem e permite um afastamento em relação aos fatos, Cubas e João de Patmos encontram-se no metaespaço da digressão visionária, espaço esse que não é neutro, dado que se reveste da peculiaridade do humor ou da gravidade do anúncio escatológico, respectivamente.

Outro ponto de semelhança entre as Memórias e o Apocalipse é a referência ao leitor. Entretanto, diferentemente do livro bíblico, no qual lemos "Bem-aventurados aqueles que leem e aqueles que ouvem as palavras da profecia e guardam as palavras nela escritas, pois o tempo está próximo", ${ }^{14}$ no romance machadiano Cubas é mais despojado e direto no diálogo com seu leitor: "Se o leitor não é dado à contemplação destes fenômenos mentais, pode saltar o capítulo; vá direto à narração". ${ }^{15}$ Não podemos, todavia, negar que, embora em diferentes peso e leveza, Cubas e João exploram a metalinguagem e se dirigem aos seus leitores. É possível compreender que Brás Cubas é mais despojado pelo fato de ele narrar suas memórias, e não a Revelação. $\mathrm{O}$ citado McGim $^{16}$ alerta-nos para o fato de que o Apocalipse provocou tanto polêmica quanto formas diversas de interpretação, mas nos lembra de que, tradicionalmente, ele é concebido como um livro profético, como o próprio texto anuncia já em seu primeiro versículo. Por outro lado, a partir do momento em que Cubas expõe os motivos que o levaram a escolher uma forma e não outra para a sua narrativa, ao voltar ao Apocalipse, podemos entender que talvez haja escolhas ali envolvidas e que elas sejam fruto

${ }^{11}$ McGIM, Bernard. Apocalipse. In: ALTER, Robert; KERMODE, Frank (Orgs.). Guia literário da Bíblia. Trad. Raul Fiker. São Paulo: Fundação Editorial da Unesp, 1997. p. 564.

12 Bíblia de Jerusalém. Gilberto da Silva Gorgulho, Ivo Storniolo, Ana Flora Anderson (Coords.). São Paulo: Paulus, 2002. p. 2165 (21:5).

${ }^{13}$ Idem, p. 2167 (22:8).

${ }^{14}$ Idem, p. 2142 (1:3).

15 ASSIS, Machado de. Obra completa. Afrânio Coutinho (Org.), cit., p. 20.

16 McGIM, Bernard. Apocalipse. In: ALTER, Robert; KERMODE, Frank (Orgs.). Guia literário da Bíblia, cit., p. 565 . 
meramente da vaidade de tornar o texto "mais galante e novo", ou seja, que isso talvez implique a existência de um homem que escreve literatura e não a de Deus que diz a verdade em premonições. Talvez seja apenas um literato e não um profeta - tal como usualmente identificamos João.

Há na narrativa de João de Patmos uma gravidade referente às mazelas dos homens e ao terror da punição prevista. Há também uma solenidade que envolve sua personagem e o contato com os sinais misteriosos e sagrados:

Vi depois, na mão direita daquele que estava sentado no trono, um livro escrito por dentro e por fora e selado com sete selos. Vi então um Anjo poderoso proclamando em alta voz: "quem é digno de abrir o livro, rompendo seus selos?" Mas ninguém no céu, nem na terra ou sob a terra era capaz de abrir nem de ler o livro. ${ }^{17}$

João recebe paulatinamente os sinais. Ele testemunha sequências de visões escatológicas, como em um filme, conforme evidencia Ivo Storniolo:

É difícil definir a fronteira que separa o gênero apocalíptico do profético [...]; mas enquanto os antigos profetas ouviam as revelações divinas e as transmitiam oralmente, o autor de um apocalipse recebia suas revelações em forma de visões, que consignava em livro. ${ }^{18}$

João se aproxima de algo tão distante, e aurático, por assim dizer, que nenhum outro ser vivo poderia se aproximar daquilo, daquele livro que continha a revelação.

Em vez de uma revelação divina, Brás Cubas narra, entre outros episódios, sua própria alucinação. Com a leitura do capítulo "O delírio", somos informados de que, antes de falecer, Brás Cubas, enfermo de pneumonia, é acometido por um delírio. Postumamente, Cubas relata-nos as sensações decorrentes desse estado de perturbação e, sobretudo, nos dá acesso às imagens dele decorrentes, como se elas se desenrolassem, cinematograficamente, de sua mente enferma. A pneumônica personagem é guiada em

\footnotetext{
${ }^{17}$ Bíblia de Jerusalém. Gilberto da Silva Gorgulho, Ivo Storniolo, Ana Flora Anderson (Coords.), cit., p. $2147(5: 1-3)$.

${ }^{18}$ STORNIOLO, Ivo. O apocalipse. In: Bíblia de Jerusalém. Gilberto da Silva Gorgulho, Ivo Storniolo, Ana Flora Anderson (Coords.), cit., p. 2139 (grifos nossos).
} 
sua visão fantástica por um hipopótamo, que a leva a conhecer as origens dos tempos e a conversar com a deusa Natureza.

Não há, assim, uma voz externa que vem-lhe falar, em nome de Deus, para toda a humanidade. Não, ele está enfermo, à beira da morte, e simplesmente, por estar em um estado alterado, delira. Cubas narra, inclusive, sua retomada de consciência. De seu metalugar, ele anuncia que vai narrar o delírio e se dirige ao leitor, conforme citamos acima, dizendo-lhe que pule aquelas páginas desimportantes, caso não seja afeito à escuta ou à compreensão de fenômenos mentais. Aparentemente, uma ambientação muito mais leve está presente na narrativa desse capítulo, afinal, não há sinais, nem livro selado, nem tampouco é um anjo celestial que vem trazer a Cubas a revelação, mas sim um hipopótamo. Trata-se verdadeiramente do absurdo, tão absurdo quanto se imaginam as alucinações. O narrador monta o hipopótamo, sem dizer se o sela antes, e cavalga pelas paisagens gélidas de seu delírio. Um algo tenso em relação à proposta despojada, irônica, galhofeira.

Colocados lado a lado, o anjo e o hipopótamo, personagens secundárias, mas com o importante papel de serem intermediários (como mensageiro ou como condutor), parecem dizer muito. O primeiro é um ser celestial, perfeito, espiritual, solene, enviado por Deus como intermediário entre Suas revelações/sinais e os homens; o segundo, um animal excêntrico, sem graça, sem elegância, desproporcional, pesado e, portanto, oprimido pela gravidade. Já não parece exatamente o animal da leveza de um humor despreocupado, sendo, pelo contrário, muito mais característico de um símbolo da testemunha, figura da desproporção causada pela violência; o peso que a gravidade oprime; o corpo desproporcional, como o texto de Cubas, em sua digressão e reflexão diante da catástrofe testemunhada que provocou a fissura que, por sua vez, é o centro de gravidade de toda a narrativa, como se todo humor se instalasse sobre um vão feito de tragédias e dramas, mas não as vindouras: as existentes e as passadas.

Percebemos aos poucos que a dualidade não é marcada por uma oposição simples: os textos ecoam suas estruturas umas nas outras, confrontam-se na leitura e confrontam a leitura. João recebe a mensagem de Deus Pai, transcendental, pertencente ao reino celeste, enquanto Brás Cubas se encontra, mas sem os tantos selos e etapas que medeiam e protelam esse encontro, no outro caso, com a própria deusa mãe, que é 
Natureza, terrena. João é um profeta e recebe de Deus as imagens do futuro, "Deus lha [a revelação] concedeu para que mostrasse aos seus servos as coisas que devem acontecer muito em breve. Ele a manifestou com sinais por meio de seu Anjo, enviado ao seu servo João [...]". ${ }^{19}$ Por seu turno, por meio de seu condutor, o hipopótamo, Cubas chega até a deusa Natureza, que lhe mostra as coisas que aconteceram, isto é, enquanto João revela o "filme" do fim do tempo, Cubas revela o do princípio dos tempos (ambos cheios de imagens violentas e trágicas) "- Engana-se - replicou o animal -, nós vamos à origem dos séculos". ${ }^{20}$ Contudo, quando finalmente se lhe vai revelar o segredo da origem, o sentido da realidade, sua consciência é recobrada e as visões do hipopótamo, da paisagem de neve e da deusa desfazem-se na figura de seu gato Sultão - nome que não nos deixa sair ainda do delírio, se nos permitimos ser arrojados ao Oriente, a outras mil e uma fantasias. A viagem de Cubas ruma, em sentido reverso, à origem, vendo os séculos passar, como se pressionada a tecla rewind do "filme": "redobrei de atenção; fitei a vista; ia enfim ver o último - o último! -; mas já então a rapidez da marcha era tal, que escapava a toda a compreensão; ao pé dela, o relâmpago seria um século". ${ }^{21}$ Assim, a visão de Cubas termina barrada pela incapacidade da compreensão diante da experiência a que teve acesso.

O termo "apocalipse" é "a transcrição de uma palavra grega que significa 'revelação'; todo apocalipse supõe, pois, uma revelação que Deus fez aos homens, revelação de coisas ocultas e só por ele conhecidas, especialmente de coisas referentes ao futuro". ${ }^{22}$ Já a palavra "delírio", segundo o Dicionário Houaiss, é de origem latina e etimologicamente significa "apartar-se do sulco da charrua, sair da linha, perder a razão [...]". ${ }^{23}$ Portanto, a palavra delírio forma-se a partir de "de" + "lira", sendo "de" "fora de" e "lira" "sulco de arado", donde se associa, "sair da linha", "sair da linha da razão", "perder a razão". Ambos os termos, "apocalipse" e "delírio", parecem ter em comum o fato de indicarem que algo sai da linha comunal, ao referirem-se à visão daquilo que é

${ }^{19}$ Bíblia de Jerusalém. Gilberto da Silva Gorgulho, Ivo Storniolo, Ana Flora Anderson (Coords.), cit., p.2147 (1:1).

${ }^{20}$ ASSIS, Machado de. Obra completa. Afrânio Coutinho (Org.), cit., p. 520.

${ }^{21}$ Idem, p. 524.

${ }^{22}$ STORNIOLO, Ivo. O apocalipse.. In: Bíblia de Jerusalém. Gilberto da Silva Gorgulho, Ivo Storniolo, Ana Flora Anderson (Coords.), cit., p. 2139.

${ }^{23}$ HOUAISS, Antônio. Dicionário Houaiss da Língua Portuguesa. Rio de Janeiro: Objetiva, 2001. 
suposto, que não se vê comumente: ou por ser negado ao homem comum, ou por ser um estado alterado da mente; de todo modo, também incomum. Mas é inegável a diferença de peso que normalmente se dá a um delírio e a uma profecia. Esta, pois, se aceita como tal, é respeitada e nela se crê; enquanto naquele, se tomado como tal, isto é, como delírio, justamente por isso, se descrê. Ora, crer ou descrer, consentir ou não é algo que cabe ao receptor, e, dessa forma, uma profecia pode ser tomada como um mero delírio, ou, ao contrário, um delírio pode ser entendido como uma profecia.

Acontece que, tal como o futuro profético do Apocalipse é exibido em cenas de guerras e de misérias, também o passado de "O delírio" se exibe acometido por flagelos e desgraças. Assim se estabelece uma equipolência que desvaloriza completamente o presságio, é como se o delírio assim dissesse: esse vaticínio não vale de nada, isso aí que João diz que Deus lhe enviou por anjos e por misteriosos sinais e por um livro sete vezes selado a que somente ele tinha acesso, em verdade, sempre foi assim e não traz revelação alguma; como sempre houve desgraças e misérias no mundo, João não traz novidade pressagiosa alguma, nenhuma revelação. Ou é como se assim Brás dissesse: ninguém detém a verdade, ou ela é redundante e tautológica. Também ao notarmos que, se ao longo de sua viagem pelas imagens futuras João é guiado por um anjo intermediador enviado por Deus e Cubas esdruxulamente é guiado por um hipopótamo, nem enviado, mas criado por seu delírio, então, somos colocados ainda diante de outras perguntas, como: tem alguma valia essa revelação sobre o que, ao cabo, sempre existiu? Não terá João sido acometido por um delírio? Não poderia João ser considerado também como um literato, divertindo-se em criar, escrever, com metalinguagens, como se exemplificou acima?

A revelação traz uma mensagem de esperança: "Bem aventurados aqueles que lavam as suas vestiduras [no sangue do Cordeiro], para que lhes assista o direito à árvore da vida [...]". ${ }^{24}$ Aos justos, será dada a recompensa da vida eterna, eis a mensagem de esperança do Apocalipse. À pergunta "- E por que Pandora?", Cubas apresenta como resposta "- Porque levo na minha bolsa os bens e os males, e o maior de todos, a esperança, consolação dos homens. Tremes?". ${ }^{25}$ A deusa Natureza não promete

\footnotetext{
${ }^{24}$ Bíblia de Jerusalém. Gilberto da Silva Gorgulho, Ivo Storniolo, Ana Flora Anderson (Coords.), cit., p. 2167 (22:14).

${ }^{25}$ ASSIS, Machado de. Obra completa. Afrânio Coutinho (Org.), cit., p.522.
} 
a vida eterna, repudia a esperança e diz que a vida é agora e que, depois, há somente o nada: "Vives: agora mesmo que ensandeceste, vives"; ${ }^{26}$ "Grande lascivo, espera-te a voluptuosidade do nada". ${ }^{27}$ Outra contraposição, essa interseção, pelo ponto da esperança. Se Deus pai escolhe os justos, a Mãe Natureza é indiferente:

- Porque já não preciso de ti [...]. Sim, egoísmo, não tenho outra lei. Egoísmo, conservação. A onça mata o novilho porque o raciocínio da onça é que ela deve viver, e se o novilho é tenro tanto melhor: eis o estatuto universal. ${ }^{28}$

Como evidencia a passagem acima, a Natureza é fria e cega. Ela não pondera nem se preocupa em fazer justiça. Ela não promete coisa alguma. Aliás, ela anuncia o "nada" por vir.

João é o escolhido, o único que ouviu e viu, o único autorizado a escrever as palavras e a descrever as cenas diretamente reveladas a si. Brás Cubas é uma pessoa qualquer, pois qualquer um pode delirar. O defunto autor mata a aura e o dogma da narrativa dita inspirada por Deus, atira-a à sarjeta. E nós ficamos com o Apocalipse mais como um poema maravilhoso, mas escrito por um homem, do que com um texto sagrado e absolutamente verdadeiro - uma maravilha sem par: ambos, o narrador profeta de Patmos e o defunto Cubas, dão-nos as cenas como se assistíssemos a um filme, já que são narrativas extremamente imagéticas e dinâmicas. São imagens maravilhosas que quase nos dão acesso ao delírio ou à visão profética. Essas contraposições podem nos convidar a olhar para as semelhanças (mesmo que invertidas) entre os dois textos, para ver na profecia não mais que um delírio, sem ancoragem em sua suposta verdade.

Não é novidade uma forma de leitura do livro de João que o relativiza em grande medida, como, por exemplo: "[As] [...] visões não têm valor por si mesmas, mas pelo simbolismo que encerram [...]". ${ }^{29}$ Tal forma de leitura coloca o Apocalipse não

\footnotetext{
${ }^{26}$ Idem, p. 521 (grifos nossos).

${ }^{27}$ Idem, 522.

${ }^{28}$ Ibidem.

${ }^{29}$ STORNIOLO, Ivo. O apocalipse. In: Bíblia de Jerusalém. Gilberto da Silva Gorgulho, Ivo Storniolo, Ana Flora Anderson (coords.), cit., p. 2139.
} 
mais como uma revelação direta ou como a própria verdade, mas como uma série de mensagens codificadas, para serem lançadas numa época em que seriam censuráveis por seu caráter de dissidência sociopolítica. Tratar-se-ia menos de uma mensagem transcendente que de uma simbolização, metaforização para ultrapassar as barreiras que o poder então em vigência impunha. João teria construído, nesse sentido, um texto que se destinava a um grupo oprimido e corria o risco de ser desmantelado pela censura. Há, contudo, outras leituras possíveis: "Muitos especialistas modernos [...] consideram o Apocalipse de João uma apresentação cíclica de visões que repetem, ou recapitulam, a mesma mensagem básica de perseguição presente, destruição iminente dos maus e recompensa dos justos". ${ }^{30}$ Assim, teríamos uma leitura que lembra o conceito nietzschiano do eterno retorno, uma forma de conceber o tempo como cíclico, que supõe a repetição eterna, sem conceber o fim ou o início.

Enquanto não se discute o estatuto de "O delírio", pois não consta que ele seja tomado de outra forma senão como literatura, talvez fazendo o movimento oposto ao que dessacraliza o Apocalipse pelas semelhanças com "O delírio", encontremos nele imagens de profecia: podemos entender que "O delírio" poderia ter sido tocado pela verdade, pela revelação; que Brás Cubas seria um personagem machadiano rajado pelas palavras e pelas imagens que atravessam os poetas e profetas desde que eles existem, em um momento de perda da razão ou de cegueira; tanto João quanto Brás Cubas eram guiados enquanto caminhavam pelos cenários de suas visões: "[...] vi chegar um hipopótamo que me arrebatou. Deixei-me ir, calado, não sei se por medo ou confiança". ${ }^{31}$ Eles eram verdadeiramente atravessados pelo filme do mundo. Quiçá mais o poder das palavras e das imagens sobre eles, Cubas e João, do que o poder e controle deles sobre elas, palavras e imagens, trariam visões que tangenciassem a verdade, mas não revelando-a. Observa-se a entrega da personagem que narra suas memórias, conforme diz Brás Cubas: "Pela minha parte fechei os olhos e deixei-me ir à ventura". ${ }^{32}$ Ao menos nesse instante em que "de-lira", Cubas se assemelha ao anjo benjaminiano: "O anjo da história deve ter esse aspecto. Seu rosto está dirigido para o passado. Onde

\footnotetext{
${ }^{30}$ McGIM, Bernard. Apocalipse. In: ALTER, Robert; KERMODE, Frank (Orgs.). Guia literário da Bíblia, cit., p. 565.

${ }^{31}$ ASSIS, Machado de. Obra completa. Afrânio Coutinho (Org.), cit., 1962, p. 520.

${ }^{32}$ Ibidem.
} 
nós vemos uma cadeia de acontecimentos, ele vê uma catástrofe única, que acumula incansavelmente ruína sobre ruína e as dispersa a nossos pés": ${ }^{33}$

Inclinei os olhos a uma das vertentes e contemplei, durante um largo tempo, ao longe, através de um nevoeiro, uma coisa única. Imagina tu, leitor, uma redução dos séculos e um desfilar de todos eles, as raças todas, todas as paixões, o tumultuo dos impérios, a guerra dos apetites, a destruição recíproca dos seres e das cousas. Tal era o espetáculo, acerbo e curioso espetáculo. A história do homem e da Terra tinha assim uma intensidade que lhe não podiam dar nem a imaginação nem a ciência, porque a ciência é mais lenta e a imaginação mais vaga, enquanto o que eu ali via era condensação viva de todos os tempos. Para descrevê-la seria preciso fixar o relâmpago. ${ }^{34}$

Referências:

ASSIS, Machado de. Obra Completa. Afrânio Coutinho (Org.). Rio de Janeiro: Nova Aguilar, 1962.

ALMEIDA, Leonardo V. A questão da biblioteca em Memórias póstumas de Brás Cubas. In: ROCHA, João Cezar de Castro (Org.). À roda de Machado de Assis: ficção, crônica e crítica. Chapecó (SC): Argos, 2006.

BENJAMIN, Walter. Sobre o conceito de história. In: . Obras escolhidas: magia e técnica, arte e política. Trad. Sergio Paulo Rouanet. São Paulo: Editora Brasiliense, 1985.

BÍBLIA DE JERUSALÉM. Gilberto da Silva Gorgulho, Ivo Storniolo, Ana Flora Anderson (Coords.). São Paulo: Paulus, 2002.

COUTINHO, Afrânio. Machado de Assis na literatura brasileira. In: ASSIS, Machado de. Obra completa. Afrânio Coutinho (Org.). Rio de Janeiro: Nova Aguilar, 1962.

HOEK, Leo H. A transposição intersemiótica: por uma classificação pragmática. Trad. Thaïs Flores N. Diniz. In: ARBEX, Márcia (Org.). Poéticas do visível. Belo Horizonte: Faculdade de Letras - UFMG, 2006.

\footnotetext{
${ }^{33}$ BENJAMIN, Walter. Sobre o conceito de história. In: Obras escolhidas: magia e técnica, arte e política. Trad. Sergio Paulo Rouanet. São Paulo: Editora Brasiliense, 1985. p. 226.

${ }^{34}$ ASSIS, Machado de. Obra completa. Afrânio Coutinho (Org.), cit., p. 523 (grifo nosso).
} 
HOUAISS, Antônio. Dicionário Houaiss da Língua Portuguesa. Rio de Janeiro: Objetiva, 2001.

LOUVEL, Liliane. Texte/image: imagens à lire, textes à voir. Rennes: Presses Universitaires de Rennes, 2002. Citado em: ARBEX, Márcia. Poéticas do visível: uma breve introdução. In: (Org.). Poéticas do visível Belo Horizonte: Faculdade de Letras - UFMG, 2006.

McGIM, Bernard. Apocalipse. In: ALTER, Robert; KERMODE, Frank (Orgs.). Guia literário da Bíblia. Trad. Raul Fiker. São Paulo: Fundação Editorial da Unesp, 1997.

MOSER, Walter. As relações entre as artes: por uma arqueologia da intermidialidade. In: Aletria. Revista de estudos de literatura. v. 14, caderno temático "Intermidialidade". Belo Horizonte, jul./dez.2006.

STIERLE, Karlheinz. Que significa a recepção dos textos ficcionais. Trad. Heidrun Krieger, Luiz Costa Lima e Peter Neumann. In: LIMA, Luiz Costa (Org.). A leitura e o leitor. Rio de Janeiro: Terra e Paz, 1979. p. 135.

STORNIOLO, Ivo. O apocalipse. In: Bíblia de Jerusalém. Gilberto da Silva Gorgulho, Ivo Storniolo, Ana Flora Anderson (Coords.). São Paulo: Paulus, 2002.

Daiane Carneiro Pimentel é licenciada e bacharel em Letras pela Universidade Federal de Minas Gerais; e mestranda em Letras na mesma instituição, na área de Teoria da Literatura, linha de pesquisa "Literatura e outros sistemas semióticos". Seus temas de interesse são literatura brasileira, Milton Hatoum, semiótica, cinema, fotografia e pintura. E-mail: <d.cpimentel@yahoo.com.br>

Glauber Pereira Quintão é bacharel em Filosofia e mestre em Letras, na área de Teoria da Literatura, dentro da linha de pesquisa "Literatura, História e Memória Cultural," pela Universidade Federal de Minas Gerais. Tem publicações a respeito dos temas judaísmo, Bíblia, genealogia literária, Moacyr Scliar. Obteve o $3^{\circ}$ lugar no Prêmio Isaías Golgher. E-mail: <glauberpereiraquintao@hotmail.com>

Recebido: $15 / 08 / 2012$

Aprovado: 29/10/2012 